\title{
Pulmonary hypertension predicts adverse cardiac events after restrictive mitral annuloplasty for severe functional mitral regurgitation
}

Satoshi Kainuma, MD, ${ }^{\mathrm{a}}$ Kazuhiro Taniguchi, MD, PhD, ${ }^{\mathrm{a}}$ Koichi Toda, MD, PhD, ${ }^{\mathrm{a}}$ Toshihiro Funatsu, MD, $\mathrm{PhD},{ }^{\mathrm{a}}$ Haruhiko Kondoh, MD, PhD, ${ }^{\mathrm{a}}$ Masami Nishino, $\mathrm{MD}, \mathrm{PhD},{ }^{\mathrm{b}}$ Takashi Daimon, $\mathrm{PhD},{ }^{\mathrm{c}}$ and Yoshiki Sawa, MD, $\mathrm{PhD}^{\mathrm{d}}$

Objectives: Pulmonary hypertension (PH) is an indicator of a poor prognosis in patients with dilated cardiomyopathy. Few studies have investigated the prognostic role of $\mathrm{PH}$ in patients undergoing restrictive mitral annuloplasty (RMA) for severe functional mitral regurgitation secondary to advanced cardiomyopathy.

Methods: A total of 46 patients undergoing RMA were classified into 3 groups on the basis of the Dopplerderived systolic pulmonary artery pressure (PAP) at baseline. Of the 46 patients, 19 had a systolic PAP less than $40 \mathrm{~mm} \mathrm{Hg}$ (mild PH group), 17 had a systolic PAP of 40 to $60 \mathrm{~mm} \mathrm{Hg}$ (moderate PH group), and 10 had a systolic PAP greater than $60 \mathrm{~mm} \mathrm{Hg}$ (severe PH group).

Results: Postoperative cardiac catheterization showed that the RMA procedure resulted in a significant reduction of the left ventricular (LV) preload and improvements in LV systolic function in all 3 groups, along with the relief of symptoms. During the follow-up period (mean, $36 \pm 19$ months), cardiac death occurred in 6 patients, readmission because of heart failure in 3 , and fatal arrhythmia in 1 . The rate of freedom from these cardiac events at 3 years was $93 \% \pm 7 \%, 88 \% \pm 8 \%$, and $56 \% \pm 17 \%$ in the mild, moderate, and severe $\mathrm{PH}$ groups $(P<.001)$. Serial echocardiography showed that significant LV reverse remodeling occurred in $89 \%, 71 \%$, and $25 \%$ of the mild, moderate, and severe $\mathrm{PH}$ groups, respectively. Multivariate Cox regression analysis identified severe $\mathrm{PH}$ (systolic PAP $>60 \mathrm{~mm} \mathrm{Hg}$ ) as a significant predictor of adverse cardiac events, as well as LV remodeling after RMA.

Conclusions: Noninvasive assessment of preoperative PH has a prognostic value in patients undergoing RMA for severe functional mitral regurgitation secondary to advanced cardiomyopathy. (J Thorac Cardiovasc Surg 2011;142:783-92)

It is well known that pulmonary hypertension $(\mathrm{PH})$ is an indicator of a poor prognosis in patients with dilated cardiomyopathy and functional mitral regurgitation (MR), ${ }^{1}$ as well as in heart transplant recipients. ${ }^{2}$ However, whether $\mathrm{PH}$ has the same prognostic value in patients who have undergone surgery for functional MR complicated by advanced cardiomyopathy is unknown.

\footnotetext{
From the Departments of Cardiovascular Surgery ${ }^{\mathrm{a}}$ and Cardiology, ${ }^{\mathrm{b}}$ Japan Labor Health and Welfare Organization, Osaka Rosai Hospital, Osaka, Japan; Department of Biostatistics, ${ }^{\text {c }}$ Hyogo College of Medicine, Hyogo, Japan; Department of Cardiovascular Surgery, ${ }^{\mathrm{d}}$ Osaka University Graduate School of Medicine, Osaka, Japan.

This research was supported by research funds to promote the hospital function of the Japan Labor Health and Welfare Organization.

Disclosures: Authors have nothing to disclose with regard to commercial support.

This study was presented in part at the American Heart Association Scientific Sessions 2009, November 14-18, 2009, Orlando, Florida.

Received for publication Aug 27, 2010; revisions received Nov 5, 2010; accepted for publication Nov 19, 2010; available ahead of print March 19, 2011

Address for reprints: Kazuhiro Taniguchi, MD, Department of Cardiovascular Surgery, Japan Labor Health and Welfare Organization, Osaka Rosai Hospital, 1179-3 Nagasone-cho, Kita-ku, Sakai, Osaka 591-8025 Japan (E-mail: kataniguchi-cvs@orh.go.jp).

$0022-5223 / \$ 36.00$

Copyright (C) 2011 by The American Association for Thoracic Surgery

doi:10.1016/j.jtcvs.2010.11.031
}

Since Bolling and colleagues ${ }^{3}$ first reported the feasibility of surgery for uncontrollable severe MR in patients with end-stage cardiomyopathy, restrictive mitral annuloplasty (RMA) has become the preferred surgical treatment of this condition. Several factors have been shown to be predictors of poor outcome after RMA. ${ }^{4-8}$ However, few investigations have assessed the influence of $\mathrm{PH}$ on symptomatic improvements, left ventricular (LV) function, or survival after RMA in patients with advanced cardiomyopathy.

In the present study, we investigated whether $\mathrm{PH}$ has a prognostic value in patients undergoing RMA for functional MR. In addition, we determined which parameters might function as predictors of postoperative outcome and reverse LV remodeling in those patients, with a focus on preoperative $\mathrm{PH}$.

\section{MATERIALS AND METHODS \\ Patients}

We examined the records of 65 consecutive patients who had undergone RMA for functional MR at our institution from March 2004 to December 2009. Of those, 46 patients were chosen as study subjects, according to the following inclusion criteria: (1) chronic heart failure with New York Heart Association (NYHA) functional class III or IV and a history of at least 1 hospitalization; (2) advanced LV remodeling, defined as a LV ejection 


$$
\begin{aligned}
& \text { Abbreviations and Acronyms } \\
& \begin{aligned}
\text { BNP } & =\text { brain natriuretic peptide } \\
\text { LV } & =\text { left ventricular } \\
\text { LVEDD } & \text { left ventricular end-diastolic } \\
& \text { dimension } \\
\text { LVEF } & =\text { left ventricular ejection fraction } \\
\text { MR } & =\text { mitral regurgitation } \\
\text { NYHA } & =\text { New York Heart Association } \\
\text { PAP } & =\text { pulmonary artery pressure } \\
\text { PH } & =\text { pulmonary hypertension } \\
\text { PVR } & =\text { pulmonary vascular resistance } \\
\text { RMA } & =\text { restrictive mitral annuloplasty } \\
\text { TR } & =\text { tricuspid regurgitation }
\end{aligned}
\end{aligned}
$$

fraction (LVEF) of less than $40 \%$ and LV end-systolic volume index greater than $60 \mathrm{ml} / \mathrm{m}^{2}$, as shown by left ventriculography; and (3) severe MR caused by restrictive leaflet motion secondary to global LV dilatation. Patients with a lesser degree of LV remodeling and ischemic MR secondary to a regional LV deformity due to inferior/posterior myocardial infarction were excluded from the present study. The patients with recent myocardial infarction ( $<3$ months), organic MR, rheumatic mitral disease, or a known noncardiac cause of $\mathrm{PH}$ were not included in the present study.

To determine whether the degree of preoperative $\mathrm{PH}$ was associated with the postoperative outcome, the patients were classified into 3 groups according to the Doppler-derived systolic pulmonary artery pressure (PAP) at baseline. Of the 46 patients, 19 had a systolic PAP of less than $40 \mathrm{~mm} \mathrm{Hg}$ (mild PH group), 17 had a systolic PAP of 40 to $60 \mathrm{~mm} \mathrm{Hg}$ (moderate PH group), and 10 had a systolic PAP greater than $60 \mathrm{~mm} \mathrm{Hg}$ (severe PH group).

The clinical characteristics and surgical data are listed in Table 1. No significant differences were found in gender, body surface area, NYHA functional class, or prevalence of complications among the 3 groups. The patients in the severe $\mathrm{PH}$ group had had a longer duration of heart failure than those in the other groups, although they were younger than the patients in the moderate $\mathrm{PH}$ group.

The related institutional ethics committees approved the present study and waived the need for individual consent for the retrospective analysis. Each patient provided written informed consent for the procedure before surgery.

\section{Echocardiographic Measurements and Calculations}

Two-dimensional and Doppler transthoracic echocardiography were performed at baseline, at 1 month after surgery (mean, $28 \pm 5$ days), and annually thereafter. The preoperative (baseline) and postoperative echocardiographic examinations at 1 month after surgery were performed within 1 day of cardiac catheterization. Transesophageal echocardiography was also performed within 1 week before surgery to confirm the severity and precise mechanism of MR in all patients. All echocardiographic studies were performed using commercially available $3.75-\mathrm{MHz}$ transducers (Toshiba, Tokyo, Japan, and Hewlett-Packard Sonos) by the same echocardiographic expert examiner (S.F.), who was unaware of the clinical status of the patients.

\section{Function and Left Atrial Dimensions}

The LV end-diastolic dimension (LVEDD), LV end-systolic dimension, and left atrial dimension was determined from 2-dimensional echocardio- graphic images in the parasternal long-axis views. The LVEF was calculated using Simpson's method with 2 apical views.

\section{Doppler-Derived Systolic PAP}

The systolic PAP was calculated by adding the systolic pressure gradient across the tricuspid valve derived from the tricuspid regurgitation (TR) to the estimated right atrial pressure. ${ }^{9,10}$ The tricuspid regurgitant signal was recorded by continuous-wave Doppler echocardiography, and its maximal velocity was measured. Using the simplified Bernoulli equation, the pressure gradient across the tricuspid valve was calculated. The right atrial pressure was estimated using the dimension of the inferior vena cava and the response to changes in respiration. ${ }^{11}$ In the present patients, a tricuspid regurgitant signal was detected in all patients during the baseline examination and in the great majority of patients during the follow-up examinations.

\section{Mitral and Tricuspid Valve Measurements}

The severity of MR and TR was graded semiquantitatively from the color flow Doppler data. In our routine assessment, MR severity was characterized as none (0), trivial (1+), mild (2+), moderate (3+), or severe (4+), depending on how far beyond the mitral valve the regurgitation extended into the left atrium. The tenting height was measured between the line connecting the annular hinge points and the leaflet coaptation point, and the coaptation length was measured directly. The area of the mitral valve orifice was determined by direct planimetry or using the pressure half-time method, and the mean transmitral diastolic gradient was calculated using the Bernoulli equation determined from continuous-wave Doppler echocardiography.

\section{Cardiac Catheterization and Hemodynamic Measurements}

Cardiac catheterization was performed before and 1 month after surgery to measure the following routine cardiac hemodynamic parameters: LV end-diastolic volume index, LV end-systolic volume index, LV systolic pressure, LV end-diastolic pressure, pulmonary capillary wedge pressure, systolic and mean PAP, transmitral diastolic pressure gradient (pulmonary capillary wedge pressure minus the LV end-diastolic pressure), right atrial pressure, systemic vascular resistance ([mean arterial pressure minus right atrial pressure] multiplied by 80 and divided by the cardiac output), and pulmonary vascular resistance (PVR) ([mean PAP minus pulmonary capillary wedge pressure] multiplied by 80 and divided by the cardiac output). Our catheterization technique has been previously described. ${ }^{12}$

\section{Surgical Procedures}

A median sternotomy was performed under a mild hypothermic cardiopulmonary bypass, with intermittent cold blood cardioplegia. Mitral valve surgery was performed through a trans-septal superior approach. Carpentier-Edwards physio rings (Carpentier Ring, Edwards Lifesciences, Irvine, Calif) were used for all RMA procedures. The ring size was determined after careful measurement of the intercommissural distance and the height of the anterior leaflet and then downsizing by 2 to 3 sizes. No other adjunct procedures were performed on the valve itself. No significant differences were found in regard to the surgical procedures among the groups, including the size of the mitral annulus ring implanted and frequency of the concomitant procedures (Table 1).

\section{Clinical Follow-up}

Clinical follow-up examinations were completed for the 43 operative survivors, with a mean duration of $36 \pm 19$ months (range, 5-77 months). After surgery, the patients were treated with standard heart failure medications, including angiotensin-converting enzyme inhibitors or angiotensin-II receptor blockers, $\beta$-blockers, and diuretics. Every 6 to 12 months, they were assessed in our department and by their primary cardiologist. The functional status was assessed according to the NYHA criteria for 
TABLE 1. Clinical characteristics and surgical data

\begin{tabular}{|c|c|c|c|c|c|}
\hline Parameter & All $(n=46)$ & Mild $(n=19)$ & Moderate $(n=17)$ & Severe $(n=10)$ & $P$ Value \\
\hline Age (y) & $64 \pm 8$ & $62 \pm 9$ & $68 \pm 6^{*}$ & $60 \pm 7$ & .02 \\
\hline Men $(\%)$ & $35(76)$ & $13(68)$ & $14(82)$ & $8(80)$ & NS \\
\hline Body surface area $\left(\mathrm{m}^{2}\right)$ & $1.7 \pm 0.2$ & $1.6 \pm 0.2$ & $1.7 \pm 0.2$ & $1.6 \pm 0.2$ & NS \\
\hline NYHA functional class & $3.2 \pm 0.4$ & $3.2 \pm 0.4$ & $3.1 \pm 0.3$ & $3.2 \pm 0.4$ & NS \\
\hline Duration of HF (mo) & $25 \pm 15$ & $18 \pm 9^{*}$ & $24 \pm 14^{*}$ & $39 \pm 15$ & $<.01$ \\
\hline Ischemic etiology $(\%)$ & $32(70)$ & $14(74)$ & $12(71)$ & $6(60)$ & NS \\
\hline Hypertension & $30(65)$ & $13(68)$ & $12(71)$ & $5(50)$ & NS \\
\hline Diabetes & $17(37)$ & $8(42)$ & $6(35)$ & $3(30)$ & NS \\
\hline Hyperlipidemia & $20(43)$ & $10(0)$ & $6(35)$ & $4(40)$ & NS \\
\hline COPD & $7(15)$ & $1(5)$ & $3(18)$ & $3(30)$ & NS \\
\hline Chronic renal disease & $16(35)$ & $7(37)$ & $3(18)$ & $6(60)$ & NS \\
\hline Peripheral vascular disease & $6(13)$ & $0(0)$ & $3(18)$ & $3(30)$ & NS \\
\hline Cerebrovascular accident & $14(30)$ & $4(21)$ & $6(35)$ & $4(40)$ & NS \\
\hline Atrial fibrillation & $21(46)$ & $9(47)$ & $8(47)$ & $4(40)$ & NS \\
\hline Previous CABG & $1(2)$ & $0(0)$ & $0(0)$ & $1(10)$ & NS \\
\hline Previous PCI & $13(28)$ & $5(26)$ & $5(29)$ & $3(30)$ & NS \\
\hline$\beta$-Blockers & $33(72)$ & $17(89)$ & $11(65)$ & $5(50)$ & NS \\
\hline ACE inhibitors & $9(20)$ & $3(16)$ & $4(24)$ & $2(20)$ & NS \\
\hline ARB & $17(37)$ & $9(47)$ & $7(41)$ & $1(10)$ & NS \\
\hline Nitrate & $12(26)$ & $6(32)$ & $3(18)$ & $3(30)$ & NS \\
\hline Diuretics & $34(74)$ & $11(58)$ & $15(82)$ & $8(80)$ & NS \\
\hline \multicolumn{6}{|l|}{ Surgical data } \\
\hline $\mathrm{CPB}(\min )$ & $240 \pm 71$ & $222 \pm 43$ & $252 \pm 69$ & $252 \pm 109$ & NS \\
\hline $\mathrm{ACC}(\min )$ & $133 \pm 43$ & $130 \pm 40$ & $147 \pm 42$ & $114 \pm 43$ & NS \\
\hline \multicolumn{6}{|l|}{ Physio ring $(\mathrm{mm})$} \\
\hline 24 & $37(80)$ & $15(79)$ & $15(82)$ & $7(70)$ & NS \\
\hline 26 & $9(20)$ & $4(21)$ & $2(12)$ & $3(30)$ & NS \\
\hline \multicolumn{6}{|l|}{ Concomitant procedure } \\
\hline CABG & $26(57)$ & $11(58)$ & $10(59)$ & $5(50)$ & NS \\
\hline TAP & $43(93)$ & $17(89)$ & $16(94)$ & $10(100)$ & NS \\
\hline Modified maze & $21(46)$ & $9(47)$ & $8(47)$ & $4(40)$ & NS \\
\hline
\end{tabular}

$N Y H A$, New York Heart Association; $H F$, heart failure; $C O P D$, chronic obstructive pulmonary disease; $C A B G$, coronary artery bypass grafting; $P C I$, percutaneous coronary intervention; $A C E$, angiotensin-converting enzyme; $A R B$, angiotensin-II receptor blocker; $C P B$, cardiopulmonary bypass; $A C C$, aortic crossclamp; $T A P$, tricuspid annuloplasty. $* P<.05$ versus severe $\mathrm{PH}$.

symptoms of heart failure and serum brain natriuretic peptide (BNP) level. A retrospective review of the medical records of these patients was performed for the preoperative and postoperative data, and the current information was obtained by interviewing the patient or the referring cardiologist. The postoperative adverse cardiac events included cardiac death, myocardial infarction, endocarditis, thromboembolism, reoperation for recurrent MR, readmission for heart failure, and fatal arrhythmia.

\section{Statistical Analysis}

The values for continuous variables are expressed as the mean \pm standard deviation. The Kruskal-Wallis and chi-square tests were used to compare the pre- and postoperative values among the 3 groups. The functional and echocardiographic variables over time were compared using repeated measures analysis of variance, followed by a Bonferroni test for individual significant differences. Univariate analysis of the predictors of adverse cardiac events was performed using a Cox proportional hazard model (see Appendix). The factors with $P<.1$ were then entered appropriately into a multivariate model. The results are summarized as hazard ratios and $95 \%$ confidence intervals. Stepwise logistic regression analysis was performed to identify predictors for failure of reverse LV remodeling (see Appendix). Kaplan-Meier and log-rank analyses were performed to compare survival and the freedom from adverse cardiac events. Correlations between the Doppler-derived and catheter-measured systolic PAP were tested using linear correlation analysis. A Bland-Altman analysis was used to further determine the agreement between the 2 modalities by calculating the bias (mean difference) and $95 \%$ limits of agreement $( \pm 2$ standard deviation). ${ }^{13} P<.05$ was considered statistically significant. The statistical analyses were performed using JMP, version 7.0 (SAS Institute, Cary, NC).

\section{RESULTS \\ Survival}

In the mild PH group, 1 early noncardiac death and 1 late fatal arrhythmia occurred. In the moderate PH group, 2 late cardiac deaths occurred. In the severe PH group, 2 early cardiac deaths, 2 late cardiac deaths, and 3 late readmissions because of heart failure occurred. None of the patients required reoperation for MR recurrence or endocarditis or presented with myocardial infarction or cerebrovascular or thromboembolic events during the follow-up period. The actuarial survival rate free from all deaths at 3 years was $95 \% \pm 5 \%, 88 \% \pm 8 \%$, and $70 \% \pm 15 \%$ in the mild, moderate, and severe $\mathrm{PH}$ groups, respectively $(P=.09$; 


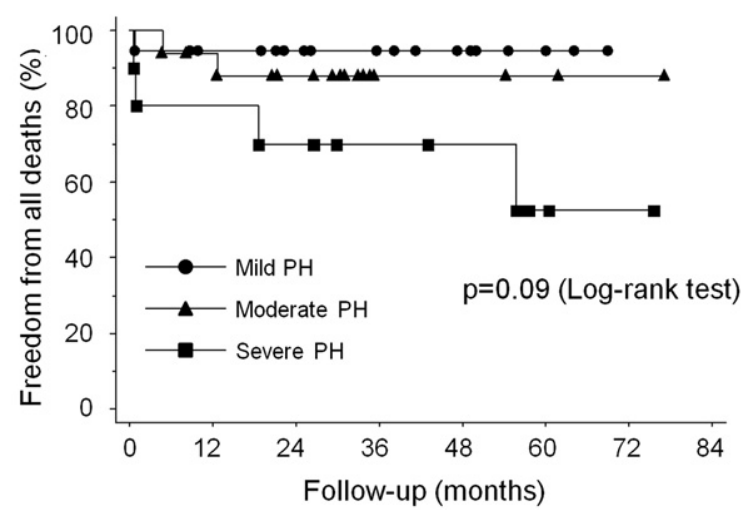

\begin{tabular}{lrrrrrrc} 
Patients at risk & 0 & 12 & 24 & 36 & 48 & 60 & 72 (month) \\
\hline Mild PH & 19 & 16 & 13 & 10 & 6 & 3 & 0 \\
Moderate PH & 17 & 15 & 12 & 3 & 3 & 2 & 1 \\
Severe PH & 10 & 8 & 7 & 5 & 4 & 2 & 1 \\
\hline Total & 46 & 39 & 32 & 18 & 13 & 7 & 2
\end{tabular}

FIGURE 1. Actuarial survival rates. Circles, triangles, and squares indicate mild, moderate and severe groups, respectively. $\mathrm{PH}$, Pulmonary hypertension. Numbers at bottom indicate patients at risk at each interval.

Figure 1). The corresponding rates of freedom from these cardiac events at 3 years were $93 \% \pm 7 \%, 88 \% \pm 8 \%$, and $56 \% \pm 17 \%(P<.001$; Figure 2$)$. The severity of preoperative $\mathrm{PH}$ was significantly associated with overall survival and the freedom from adverse cardiac events.

\section{Acute Hemodynamic Changes After RMA}

Preoperatively, all patients showed impairment of systemic and pulmonary hemodynamic conditions, the severity of which increased with the severity of the PH (Table 2, Figure 3). The systolic and mean PAP and PVR in the severe $\mathrm{PH}$ group were significantly greater than those in the other 2 groups.

From baseline to 1 month after surgery, the patients in the mild $\mathrm{PH}$ group showed good functional improvement, but those in the severe PH group showed less improvement. The patients in the moderate PH group showed improvement that was intermediate between that of the mild and severe PH groups. The LV volumes significantly decreased, and the LVEF improved in all 3 groups, although patients in the severe $\mathrm{PH}$ group showed less improvement in those parameters than in the other 2 groups. The LV systolic pressures did not change; however, the LV end-diastolic pressure decreased significantly in all groups.

In the patients with mild and moderate $\mathrm{PH}$, the cardiac index increased significantly, the systemic vascular resistance decreased, and the systolic and mean PAP and PVR remained unchanged. In contrast, in the severe PH group, the cardiac index and systemic vascular resistance remained unchanged, and the systolic and mean PAP and the PVR significantly decreased. In the severe $\mathrm{PH}$ group, both systolic and mean PAP and PVR significantly decreased; Importantly, in patients with severe PH, the systolic PAP

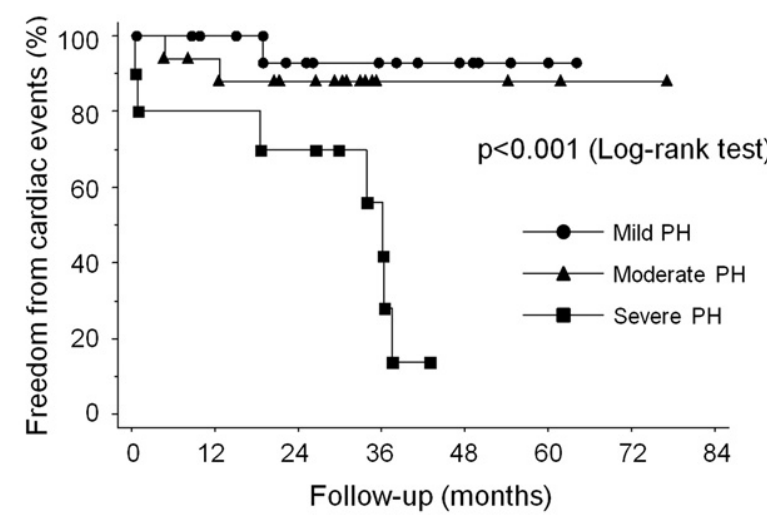

\begin{tabular}{lrrrrrrc} 
Patients at risk & 0 & 12 & 24 & 36 & 48 & 60 & 72 (month) \\
\hline Mild PH & 19 & 16 & 12 & 9 & 5 & 2 & 0 \\
Moderate PH & 17 & 15 & 12 & 3 & 3 & 2 & 1 \\
Severe PH & 10 & 8 & 7 & 4 & 0 & 0 & 0 \\
\hline Total & 46 & 39 & 31 & 16 & 8 & 4 & 1
\end{tabular}

FIGURE 2. Freedom from adverse cardiac events. Circles, triangles, and squares indicate mild, moderate, and severe groups, respectively. $\mathrm{PH}$, Pulmonary hypertension. Numbers at bottom indicate patients at risk at each interval.

and PVR at 1 month after surgery were significantly greater than those in the mild PH group and remained substantially abnormal, suggesting the persistence of abnormal pulmonary hemodynamics.

\section{Serial Echocardiographic Examinations}

LV dimensions and function and left atrial dimensions. In the mild and moderate groups, the LVEDD, left ventricular end-systolic dimension, and left atrial dimension had decreased significantly and the LVEF had improved at 1 month after surgery (Table 3, Figure 4). Also, these improvements (reverse remodeling) persisted during the follow-up period. In the severe PH group, the LV dimensions remained unchanged at 1 month after surgery and were significantly greater than the other 2 groups. In addition, the severe PH group had lower LVEF values than the mild and moderate PH groups at all follow-up examinations. Doppler-derived systolic PAP. In the mild and moderate PH groups, the mean systolic PAP at 1 month after surgery had remained or returned to a normal range in most patients. Those values had stabilized within the normal range during the follow-up period, along with an improvement in MR. In contrast, the mean systolic PAP in the severe PH group had decreased at 1 month after surgery; however, the values had never returned to a normal range, regardless of significant improvement in MR. The systolic PAP in the severe PH group had gradually worsened for a period of years, in contrast to the LV systolic function and LV dimension.

Mitral valve performance and measurements. Serial examinations showed significant improvements in MR in all groups, with optimal mitral valve geometry in terms of 
TABLE 2. Acute hemodynamic changes

\begin{tabular}{|c|c|c|c|c|c|c|c|c|}
\hline \multirow[b]{2}{*}{ Variable } & \multicolumn{2}{|c|}{ All } & \multicolumn{2}{|c|}{ Mild } & \multicolumn{2}{|c|}{ Moderate } & \multicolumn{2}{|c|}{ Severe } \\
\hline & $\begin{array}{l}\text { Baseline } \\
(n=46)\end{array}$ & $\begin{array}{c}\text { Discharge } \\
(\mathbf{n}=\mathbf{3 3})\end{array}$ & $\begin{array}{l}\text { Baseline } \\
(\mathrm{n}=19)\end{array}$ & $\begin{array}{c}\text { Discharge } \\
(\mathbf{n}=13)\end{array}$ & $\begin{array}{l}\text { Baseline } \\
(\mathbf{n}=17)\end{array}$ & $\begin{array}{c}\text { Discharge } \\
(n=14)\end{array}$ & $\begin{array}{l}\text { Baseline } \\
(\mathbf{n}=10)\end{array}$ & $\begin{array}{c}\text { Discharge } \\
(\mathrm{n}=6)\end{array}$ \\
\hline LVEDVI $\left(\mathrm{mL} / \mathrm{m}^{2}\right)$ & $140 \pm 38$ & $110 \pm 35^{*}$ & $129 \pm 29$ & $105 \pm 22 *$ & $144 \pm 45$ & $106 \pm 42 *$ & $155 \pm 35$ & $133 \pm 41^{*}$ \\
\hline $\operatorname{LVESVI}\left(\mathrm{mL} / \mathrm{m}^{2}\right)$ & $104 \pm 34$ & $59 \pm 29^{*}$ & $94 \pm 25$ & $53 \pm 17^{*}$ & $105 \pm 40$ & $54 \pm 28^{*}$ & $120 \pm 33$ & $85 \pm 40 *$ \\
\hline $\operatorname{LVEF}(\%)$ & $26 \pm 7$ & $37 \pm 12 *$ & $27 \pm 8$ & $39 \pm 10^{*}$ & $28 \pm 7$ & $38 \pm 13^{*}$ & $23 \pm 6$ & $32 \pm 16^{*}$ \\
\hline LVSP (mm Hg) & $116 \pm 22$ & $120 \pm 15$ & $114 \pm 19$ & $120 \pm 14$ & $120 \pm 20$ & $121 \pm 15$ & $111 \pm 29$ & $118 \pm 20$ \\
\hline LVEDP (mm Hg) & $20 \pm 8$ & $12 \pm 4^{*}$ & $17 \pm 8 \dagger$ & $10 \pm 3^{*}$ & $20 \pm 5$ & $14 \pm 4^{*}$ & $26 \pm 8$ & $14 \pm 5^{*}$ \\
\hline PCWP (mm Hg) & $20 \pm 8$ & $15 \pm 5^{*}$ & $16 \pm 8 \dagger$ & $13 \pm 4$ & $20 \pm 6$ & $16 \pm 4$ & $27 \pm 8$ & $17 \pm 7$ \\
\hline Systolic PAP (mm Hg) & $44 \pm 15$ & $35 \pm 8 *$ & $34 \pm 10 \dagger$ & $31 \pm 7 \dagger$ & $43 \pm 10 \dagger$ & $38 \pm 8$ & $59 \pm 16$ & $39 \pm 10^{*}$ \\
\hline Mean PAP $(\mathrm{mm} \mathrm{Hg})$ & $29 \pm 10$ & $23 \pm 5^{*}$ & $22 \pm 7 \dagger$ & $20 \pm 4 \dagger$ & $29 \pm 7 \dagger$ & $25 \pm 5$ & $40 \pm 10$ & $26 \pm 5^{*}$ \\
\hline RAP (mm Hg) & $8.2 \pm 4.5$ & $8.9 \pm 3.0$ & $6.7 \pm 3.8$ & $8.0 \pm 2.9$ & $7.9 \pm 4.8$ & $9.7 \pm 2.7$ & $10.0 \pm 4.2$ & $9.0 \pm 4.0$ \\
\hline $\mathrm{CI}\left(\mathrm{L} / \mathrm{min} / \mathrm{m}^{2}\right)$ & $2.6 \pm 0.6$ & $3.0 \pm 0.7 *$ & $2.6 \pm 0.5$ & $3.1 \pm 0.7 * \dagger$ & $2.7 \pm 0.6$ & $3.0 \pm 0.7^{* \dagger}$ & $2.2 \pm 0.6$ & $2.2 \pm 0.4$ \\
\hline TMPG (mm Hg) & $0.4 \pm 6.4$ & $2.5 \pm 3.1$ & $0.1 \pm 6.6$ & $2.8 \pm 3.1$ & $0.2 \pm 7.0$ & $2.1 \pm 2.9$ & $1.4 \pm 5.5$ & $2.7 \pm 3.7$ \\
\hline SVR (dynes $\cdot \mathrm{s} \cdot \mathrm{cm}^{-5}$ ) & $1520 \pm 380$ & $1320 \pm 420^{*}$ & $1590 \pm 340$ & $1310 \pm 310^{*}$ & $1490 \pm 470$ & $1240 \pm 290 *$ & $1470 \pm 310$ & $1520 \pm 740$ \\
\hline PVR (dynes $\cdot \mathrm{s} \cdot \mathrm{cm}^{-5}$ ) & $171 \pm 90$ & $137 \pm 54$ & $127 \pm 62 \dagger$ & $123 \pm 44 \dagger$ & $162 \pm 48 \dagger$ & $143 \pm 63$ & $243 \pm 122$ & $147 \pm 53^{*}$ \\
\hline
\end{tabular}

LVEDVI, Left ventricular end-diastolic volume index; $L V E S V I$, left ventricular end-systolic volume index; $L V E F$, left ventricular ejection fraction; $P C W P$, pulmonary capillary wedge pressure; $P A P$, pulmonary artery pressure; $R A P$, right atrial pressure; $C I$, cardiac index; $T M P G$, transmitral pressure gradient; $S V R$, systemic vascular resistance; $P V R$, pulmonary vascular resistance. ${ }^{*} P<.05$ versus variables at baseline in each group. $\dagger P<.05$ versus severe $\mathrm{PH}$ group at each point.

a decreased tenting height and adequate coaptation length. No significant differences were found postoperatively in the changes in MR grade, TR grade, coaptation length, tenting height, mitral valve orifice area, or mean transmitral pressure gradient among the 3 study groups.

\section{Symptoms and Serum BNP Levels}

The NYHA functional improvements and changes in serum BNP levels were not significantly associated with the preoperative severity of $\mathrm{PH}$ (Figure 5). The patients in the severe $\mathrm{PH}$ group tended to show less improvement. In
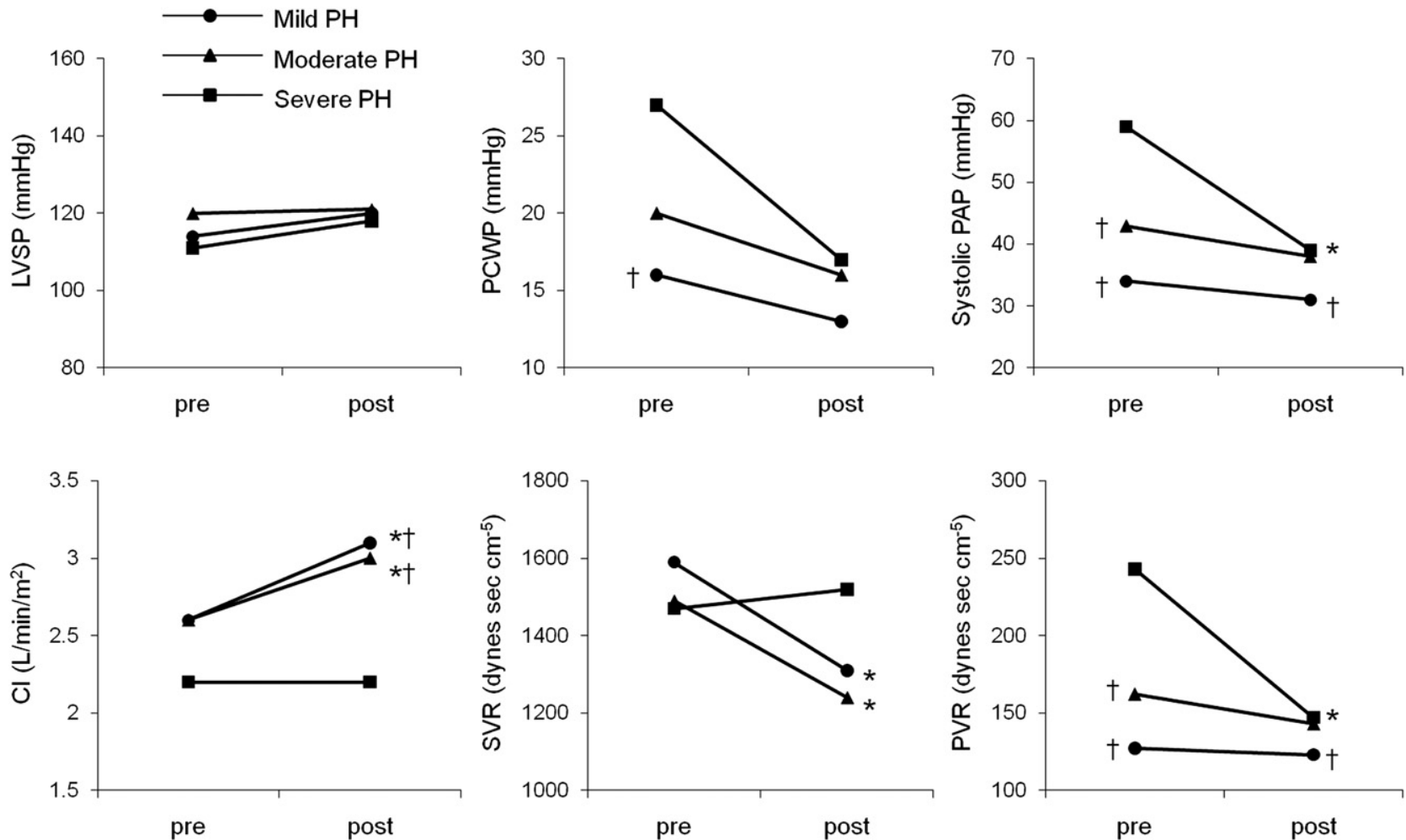

FIGURE 3. Acute hemodynamic changes after restrictive mitral annuloplasty. $* P<.05$ versus value at baseline, $\dagger P<.05$ versus value for severe pulmonary hypertension $(P H)$ group. LVSP, Left ventricular systolic pressure; $P C W P$, pulmonary capillary wedge pressure; $P A P$, pulmonary artery pressure; $C I$, cardiac index; SVR, systemic vascular resistance; $P V R$, pulmonary vascular resistance. Circles, triangles, and squares indicate mild, moderate, and severe groups, respectively. 
TABLE 3. Serial echocardiographic and functional variables

\begin{tabular}{|c|c|c|c|c|c|}
\hline Variable & Baseline & $1 \mathrm{mo}$ & $1 y$ & $2 y$ & $P$ Value \\
\hline \multicolumn{6}{|l|}{ LVEDD (mm) } \\
\hline All & $66 \pm 6$ & $60 \pm 7 *$ & $60 \pm 8^{*}$ & $59 \pm 8^{*}$ & $<.01$ \\
\hline Mild PH group & $66 \pm 6$ & $58 \pm 6^{*} \dagger$ & $58 \pm 9^{*}$ & $57 \pm 9 *$ & $<.01$ \\
\hline Moderate PH group & $65 \pm 6$ & $58 \pm 7 * \dagger \dagger$ & $58 \pm 5^{*}$ & $56 \pm 4^{*}$ & $<.01$ \\
\hline Severe PH group & $69 \pm 6$ & $67 \pm 6$ & $66 \pm 8$ & $64 \pm 10$ & NS \\
\hline \multicolumn{6}{|l|}{ LVESD (mm) } \\
\hline All & $55 \pm 7$ & $48 \pm 10^{*}$ & $45 \pm 10^{*}$ & $44 \pm 12^{*}$ & $<.01$ \\
\hline Mild PH group & $54 \pm 7 \dagger$ & $45 \pm 8^{*} \uparrow$ & $42 \pm 9^{*}$ & $40 \pm 11^{*}$ & $<.01$ \\
\hline Moderate $\mathrm{PH}$ group & $53 \pm 7 \dagger$ & $46 \pm 10^{*} \uparrow$ & $43 \pm 10^{*}$ & $41 \pm 6^{*}$ & $<.01$ \\
\hline Severe PH group & $61 \pm 6$ & $58 \pm 7$ & $52 \pm 11$ & $52 \pm 13$ & NS \\
\hline \multicolumn{6}{|l|}{ LVEF (\%) } \\
\hline All & $32 \pm 5$ & $39 \pm 8^{*}$ & $44 \pm 7 *$ & $45 \pm 7 *$ & $<.01$ \\
\hline Mild PH group & $34 \pm 4 \dagger$ & $42 \pm 5^{*} \dagger$ & $46 \pm 7 * \dagger$ & $49 \pm 6^{*} \dagger$ & $<.01$ \\
\hline Moderate PH group & $33 \pm 6 \dagger$ & $40 \pm 10^{*} \dagger$ & $45 \pm 5^{* \dagger}$ & $45 \pm 5^{*} \dagger$ & $<.01$ \\
\hline Severe PH group & $29 \pm 4$ & $31 \pm 6$ & $37 \pm 9^{*}$ & $39 \pm 8^{*}$ & .02 \\
\hline \multicolumn{6}{|l|}{ LA dimension (mm) } \\
\hline All & $51 \pm 7$ & $45 \pm 6^{*}$ & $48 \pm 5^{*}$ & $48 \pm 5^{*}$ & $<.01$ \\
\hline Mild PH group & $49 \pm 6$ & $44 \pm 6^{*} \dagger$ & $48 \pm 5$ & $47 \pm 5$ & .03 \\
\hline Moderate PH group & $51 \pm 6$ & $45 \pm 3^{*}$ & $48 \pm 5$ & $49 \pm 4$ & $<.01$ \\
\hline Severe PH group & $52 \pm 9$ & $50 \pm 7$ & $50 \pm 6$ & $49 \pm 8$ & NS \\
\hline \multicolumn{6}{|l|}{ Systolic PAP (mm Hg) } \\
\hline All & $47 \pm 15$ & $36 \pm 8^{*}$ & $38 \pm 9^{*}$ & $37 \pm 13^{*}$ & $<.01$ \\
\hline Mild PH group & $33 \pm 4 \dagger$ & $33 \pm 6$ & $32 \pm 9$ & $29 \pm 9$ & NS \\
\hline Moderate PH group & $48 \pm 6 \dagger$ & $36 \pm 7^{*}$ & $36 \pm 8^{*}$ & $36 \pm 10^{*}$ & .02 \\
\hline Severe PH group & $70 \pm 9$ & $42 \pm 8^{*}$ & $50 \pm 11^{*}$ & $54 \pm 17$ & .01 \\
\hline \multicolumn{6}{|l|}{ MR grade } \\
\hline All & $3.6 \pm 0.5$ & $0.9 \pm 0.7^{*}$ & $0.9 \pm 0.7^{*}$ & $1.0 \pm 0.7^{*}$ & $<.01$ \\
\hline Mild PH group & $3.6 \pm 0.5$ & $0.8 \pm 0.4^{*}$ & $0.8 \pm 0.7^{*}$ & $0.8 \pm 0.6^{*}$ & $<.01$ \\
\hline Moderate PH group & $3.6 \pm 0.5$ & $0.9 \pm 0.7^{*}$ & $0.8 \pm 0.6^{*}$ & $1.0 \pm 0.0^{*}$ & $<.01$ \\
\hline Severe PH group & $3.8 \pm 0.5$ & $1.3 \pm 1.2^{*}$ & $1.0 \pm 0.9^{*}$ & $1.3 \pm 1.0^{*}$ & .02 \\
\hline \multicolumn{6}{|l|}{ TR grade } \\
\hline All & $2.3 \pm 1.1$ & $0.9 \pm 0.6^{*}$ & $0.9 \pm 0.6^{*}$ & $1.0 \pm 0.6^{*}$ & $<.01$ \\
\hline Mild PH group & $2.3 \pm 1.2$ & $0.8 \pm 0.7^{*}$ & $0.8 \pm 0.6^{*}$ & $1.0 \pm 0.0^{*}$ & $<.01$ \\
\hline Moderate PH group & $2.2 \pm 1.0$ & $0.8 \pm 0.4^{*}$ & $0.8 \pm 0.4^{*}$ & $1.2 \pm 0.8^{*}$ & .02 \\
\hline Severe PH group & $2.5 \pm 1.3$ & $1.1 \pm 0.6^{*}$ & $1.3 \pm 0.7^{*}$ & $1.2 \pm 0.4^{*}$ & .03 \\
\hline \multicolumn{6}{|l|}{ Tenting height (mm) } \\
\hline All & $7.9 \pm 2.4$ & $4.2 \pm 1.9^{*}$ & $3.8 \pm 0.9^{*}$ & $4.0 \pm 1.4^{*}$ & $<.01$ \\
\hline Mild PH group & $6.7 \pm 2.3$ & $4.7 \pm 2.2^{*}$ & $4.0 \pm 1.1^{*}$ & $3.6 \pm 0.4^{*}$ & $<.01$ \\
\hline Moderate PH group & $8.0 \pm 2.0$ & $3.7 \pm 1.2^{*}$ & $3.6 \pm 0.7^{*}$ & $4.3 \pm 2.0^{*}$ & $<.01$ \\
\hline Severe PH group & $10.1 \pm 1.7$ & $4.1 \pm 2.3^{*}$ & $3.8 \pm 0.8^{*}$ & $4.2 \pm 0.3^{*}$ & $<.01$ \\
\hline \multicolumn{6}{|l|}{ Coaptation length (mm) } \\
\hline All & $4.1 \pm 1.5$ & $8.0 \pm 2.4^{*}$ & $8.2 \pm 1.1^{*}$ & $7.9 \pm 1.1^{*}$ & $<.01$ \\
\hline Mild PH group & $4.4 \pm 1.7$ & $7.4 \pm 1.8^{*}$ & $8.1 \pm 1.4^{*}$ & $8.0 \pm 1.3^{*}$ & $<.01$ \\
\hline Moderate PH group & $4.2 \pm 1.5$ & $8.7 \pm 3.0^{*}$ & $8.2 \pm 1.0^{*}$ & $7.9 \pm 1.0^{*}$ & $<.01$ \\
\hline Severe PH group & $3.0 \pm 0.7$ & $7.9 \pm 2.0^{*}$ & $8.3 \pm 1.3^{*}$ & $7.7 \pm 1.3^{*}$ & $<.01$ \\
\hline \multicolumn{6}{|c|}{ Effective orifice area $\left(\mathrm{cm}^{2}\right)$} \\
\hline All & & $2.6 \pm 0.3$ & $2.6 \pm 0.4$ & $2.5 \pm 0.4$ & NS \\
\hline Mild PH group & & $2.6 \pm 0.3$ & $2.6 \pm 0.3$ & $2.5 \pm 0.3$ & NS \\
\hline Moderate PH group & & $2.6 \pm 0.4$ & $2.6 \pm 0.3$ & $2.5 \pm 0.3$ & NS \\
\hline Severe PH group & & $2.6 \pm 0.4$ & $2.7 \pm 0.4$ & $2.6 \pm 0.4$ & NS \\
\hline
\end{tabular}

contrast, in the mild and moderate PH groups, the NYHA functional class improved significantly, and the improvement persisted during the follow-up period, along with reduced serum BNP levels.

\section{Prediction for Reverse LV Remodeling}

When substantial reverse $\mathrm{LV}$ remodeling was defined as a $10 \%$ reduction in the LVEDD, LV reverse remodeling was seen in $16(89 \%)$ of 18 patients with mild $\mathrm{PH}, 12$ 
TABLE 3. Continued

\begin{tabular}{|c|c|c|c|c|c|}
\hline Variable & Baseline & $1 \mathrm{mo}$ & $1 y$ & $2 y$ & $P$ Value \\
\hline \multicolumn{6}{|l|}{ TMPG (mm Hg) } \\
\hline All & & $4.2 \pm 1.5$ & $4.3 \pm 1.6$ & $4.7 \pm 2.3$ & NS \\
\hline Mild PH group & & $4.7 \pm 1.6$ & $4.6 \pm 1.3$ & $4.9 \pm 2.0$ & NS \\
\hline Moderate PH group & & $3.7 \pm 1.3$ & $3.9 \pm 1.3$ & $4.7 \pm 2.1$ & NS \\
\hline Severe PH group & & $4.4 \pm 1.4$ & $4.5 \pm 2.6$ & $4.5 \pm 3.4$ & NS \\
\hline
\end{tabular}

(71\%) of 17 patients with moderate $\mathrm{PH}$, and $2(25 \%)$ of 8 with severe PH $(P=\mathrm{NS})$ at their most recent examination (Table 4). Univariate analysis identified LV systolic dysfunction $(P=.022)$, a longer duration of heart failure $(P=.01)$, and severe PH (systolic PAP $>60 \mathrm{~mm} \mathrm{Hg}$; $P=.004)$ as important predictors of failure of reverse LV remodeling. In addition, multivariate analysis identified severe $\mathrm{PH}$ as a significant predictor.

\section{Prediction of Postoperative Adverse Cardiac Events}

Finally, the potential predictors of postoperative adverse cardiac events were examined using a Cox proportional hazard model (Table 5). Univariate analysis identified preoperative $\mathrm{LV}$ systolic dysfunction $(P=.04)$, a longer duration of heart failure $(P=.021)$, and severe PH (systolic PAP $>60 \mathrm{~mm}$ $\mathrm{Hg} ; P=.002$ ) as important predictors. In addition, multivariate analysis identified severe $\mathrm{PH}$ as a significant predictor.

\section{DISCUSSION}

The results of the present study suggest that $\mathrm{PH}$ in patients with advanced cardiomyopathy undergoing RMA is significantly associated with adverse short-term clinical outcome in terms of overall survival, adverse cardiac events (including cardiac death, readmission for heart failure, and fatal arrhythmia), improvements in NYHA functional class and serum BNP levels, acute hemodynamic changes, and serial echocardiographic changes in LV dimensions and function. Our findings have also demonstrated that severe $\mathrm{PH}$ (systolic PAP $>60 \mathrm{~mm} \mathrm{Hg}$ ) was an important hemodynamic predictor of adverse cardiac events, as well as failure of LV reverse remodeling after surgical treatment for functional MR and LV dysfunction.

In previous studies, clinical variables such as advanced age, preoperative hemodialysis and diabetes ${ }^{4}$ larger LV dimensions, ${ }^{5,6}$ and nonischemic etiology and a longer duration of heart failure ${ }^{7}$ were shown to be significantly associated with poor outcomes after RMA. In addition, the more sophisticated echocardiographic parameters of LV systolic and diastolic dysfunction such as LVEDD $(>65 \mathrm{~mm})$ and left ventricular end-systolic dimension $(>51 \mathrm{~mm}),{ }^{8}$ myocardial performance index, systolic sphericity, wall motion score index ${ }^{14,15}$ restrictive LV filling
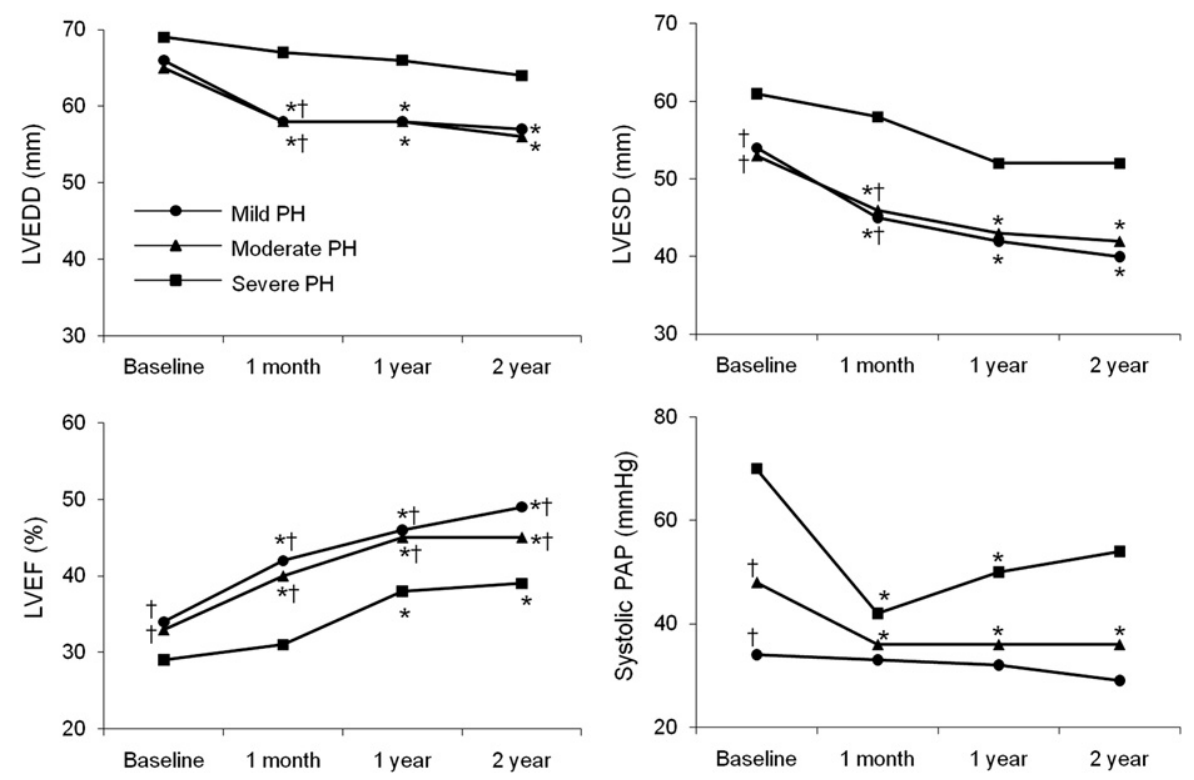

FIGURE 4. Serial echocardiographic changes after restrictive mitral annuloplasty. $* P<.05$ versus value at baseline, $\dagger P<.05$ versus value for severe PH group. $L V E D D$, Left ventricular end-diastolic dimension; $L V E F$, left ventricular ejection fraction; $L V E S D$, left ventricular end-systolic dimension; $P A P$, pulmonary artery pressure; $P H$, pulmonary hypertension. 

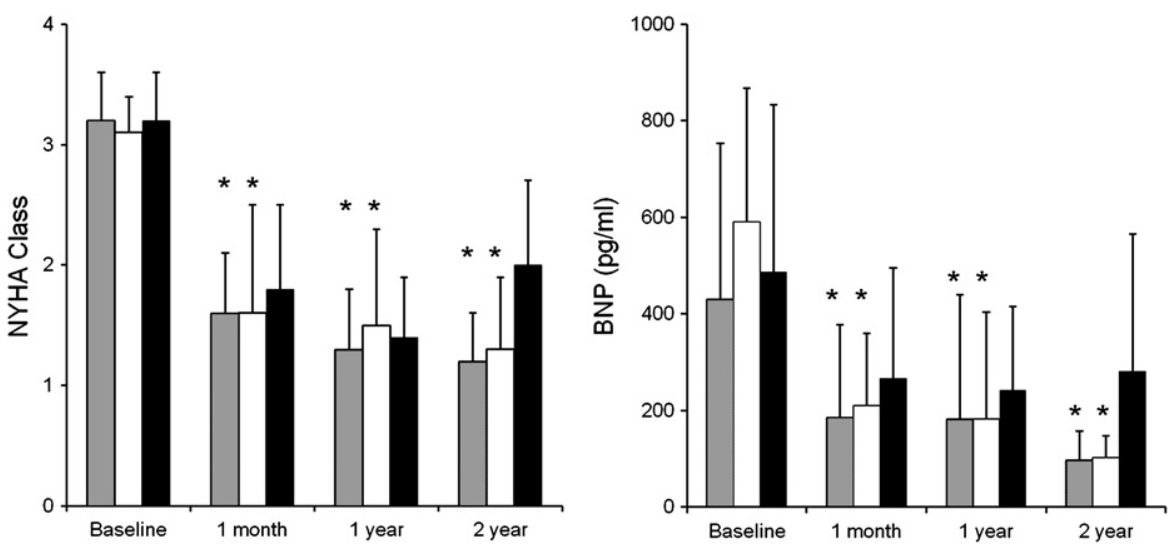

FIGURE 5. Serial changes in New York Heart Association $(N Y H A)$ functional class and serum brain natriuretic peptide $(B N P)$ level. *P<.05 versus value at baseline. Gray, white, and black bars indicate mild, moderate, and severe groups, respectively.

pattern and mitral deceleration time $(<140 \mathrm{~ms})^{16}$ have been reported to be strong predictors of poor outcome or a lack of LV reverse remodeling after RMA. These parameters have also been shown to predict late MR recurrence after mitral annuloplasty. The present results have suggested that the $\mathrm{PH}$ level is a strong predictor of outcome after RMA and also provided additional important prognostic information that is complementary to the classic echocardiographic parameters of LV systolic and diastolic dysfunction.

The etiologies of $\mathrm{PH}$ in patients with cardiomyopathy are heterogeneous, and the determinants of its reversibility after an annuloplasty procedure have not been fully clarified. Classically, $\mathrm{PH}$ in patients with cardiomyopathy has been attributed to elevated LV filling pressures, reactive pulmonary arterial vasoconstriction, pulmonary vascular remodeling, or all three ${ }^{17}$; it has also been associated with functional MR. ${ }^{18}$ The increased PAP associated with early-stage cardiomyopathy prin-

TABLE 4. Predictors of failure in left ventricular reverse remodeling

\begin{tabular}{|c|c|c|c|c|c|c|}
\hline \multirow[b]{2}{*}{ Variable } & \multicolumn{3}{|c|}{ Univariate } & \multicolumn{3}{|c|}{ Multivariate } \\
\hline & $\begin{array}{c}P \\
\text { Value }\end{array}$ & $\begin{array}{c}\text { Odds } \\
\text { ratio }\end{array}$ & $\begin{array}{c}95 \% \\
\text { CI }\end{array}$ & $\begin{array}{c}P \\
\text { Value }\end{array}$ & $\begin{array}{l}\text { Odds } \\
\text { ratio }\end{array}$ & $\begin{array}{c}95 \% \\
\text { CI } \\
\end{array}$ \\
\hline Age & NS & & & & & \\
\hline Ischemic etiology & NS & & & & & \\
\hline Duration of HF & .01 & 1.1 & $1.02-1.15$ & NS & & \\
\hline History of VT & NS & & & & & \\
\hline LVEDD (continuous) & NS & & & & & \\
\hline LVEDD $(>65 \mathrm{~mm})$ & NS & & & & & \\
\hline LVESD (continuous) & NS & & & & & \\
\hline $\operatorname{LVESD}(>50 \mathrm{~mm})$ & NS & & & & & \\
\hline LA dimension $(\mathrm{mm})$ & NS & & & & & \\
\hline LVEF $(\%)$ & .02 & 0.8 & $0.70-0.97$ & NS & & \\
\hline Severe $\mathrm{PH}^{*}$ & .004 & 25.7 & $4.3-155$ & .03 & 10.0 & $1.3-75$ \\
\hline MR grade & NS & & & & & \\
\hline TR grade & NS & & & & & \\
\hline
\end{tabular}

cipally results from elevated LV filling pressures. ${ }^{18}$ In addition, longstanding elevation of LV filling pressures can lead to several histologic changes in pulmonary circulation, including medial hypertrophy of arterioles, intimal fibroproliferation, and arterialization of the pulmonary veins. ${ }^{17}$ These changes have also been associated with neurohumoral activation, in particular of endothelin- $1,{ }^{19,20}$ a potent vasoconstrictor that is markedly increased in patients with advanced heart failure. These pathophysiologic changes are dependent on the chronicity and severity of $\mathrm{PH}$ and can initially be reversible, although the conditions can eventually become irreversible. ${ }^{17}$

The changes in pulmonary hemodynamics seen in the present severe $\mathrm{PH}$ group were consistent with this sequence of $\mathrm{PH}$ progression. The patients in the severe $\mathrm{PH}$ group had had a longer duration of heart failure and greater PVR values before surgery. Furthermore, the mean PVR value in this group remained considerably elevated at 1 month

TABLE 5. Predictors of adverse cardiac events

\begin{tabular}{|c|c|c|c|c|c|c|}
\hline \multirow[b]{2}{*}{ Variable } & \multicolumn{3}{|c|}{ Univariate } & \multicolumn{3}{|c|}{ Multivariate } \\
\hline & $\begin{array}{c}P \\
\text { Value }\end{array}$ & $\begin{array}{c}\text { Hazard } \\
\text { ratio }\end{array}$ & $\begin{array}{c}95 \% \\
\text { CI }\end{array}$ & $\begin{array}{c}P \\
\text { Value }\end{array}$ & $\begin{array}{c}\text { Hazard } \\
\text { ratio }\end{array}$ & $\begin{array}{c}\mathbf{9 5} \% \\
\text { CI }\end{array}$ \\
\hline Age & NS & & & & & \\
\hline Ischemic etiology & NS & & & & & \\
\hline Duration of HF & .02 & 1.05 & $1.01-1.10$ & NS & & \\
\hline History of VT & NS & & & & & \\
\hline LVEDD (continuous) & NS & & & & & \\
\hline LVEDD $(>65 \mathrm{~mm})$ & NS & & & & & \\
\hline LVESD (continuous) & NS & & & & & \\
\hline LVESD $(>50 \mathrm{~mm})$ & NS & & & & & \\
\hline LA dimension $(\mathrm{mm})$ & NS & & & & & \\
\hline LVEF (\%) & .04 & 0.89 & $0.79-0.96$ & NS & & \\
\hline Severe $\mathrm{PH}^{*}$ & .002 & 9.1 & $2.3-35$ & .04 & 6.9 & $1.1-44$ \\
\hline MR grade & NS & & & & & \\
\hline TR grade & NS & & & & & \\
\hline
\end{tabular}


after surgery. The elevated PAP levels $(>40 \mathrm{~mm} \mathrm{Hg}$ ) persisted at all follow-up examinations, suggesting the presence of irreversible pulmonary vascular disease. In contrast, the moderate $\mathrm{PH}$ group showed a decline in the systolic PAP without a change in the lowered PVR at discharge. Also, the lower PAP values were maintained until the latest follow-up examination, suggesting that $\mathrm{PH}$ was reversible in these patients. Thus, our findings emphasize the importance of assessing PVR and the degree of pulmonary vascular remodeling. In addition, our results might support the use of surgery for patients with medically uncontrollable severe functional MR before the pulmonary vascular disease becomes irreversible.

The degree of PH is not only related to the severity of LV systolic dysfunction, but is also strongly associated with the LV diastolic dysfunction (ie, a greater level of PH has been associated with a shorter mitral deceleration time). ${ }^{18}$ Gelsomino and colleagues ${ }^{21}$ reported that the Dopplerderived mitral deceleration time was prognostic for LV reverse remodeling after undersized mitral annuloplasty. Our results are not necessarily inconsistent with those of previous studies, because a strong correlation between the Doppler-derived systolic PAP and mitral deceleration time has been reported. ${ }^{18}$ Also, the prevalence of a restrictive filling pattern has been inversely related to the LVEF. $\mathrm{PH}$ has also been significantly associated with right ventricular function and right heart hemodynamics. In contrast, the right ventricular EF will correlate with the systolic PAP and is an independent predictor of survival in patients with moderate heart failure. ${ }^{22}$ This association between $\mathrm{PH}$ and right ventricular dysfunction could explain why the level of PH provides additional prognostic information beyond the LV systolic and diastolic dysfunction variables.

It remains controversial whether patients with end-stage heart failure and functional MR can benefit from RMA. ${ }^{23-25}$ In our study, patients with mild and moderate PH (Dopplerderived PAP $<60 \mathrm{~mm} \mathrm{Hg}$ ) showed functional improvement and satisfactory long-term survival. In contrast, those with severe PH (systolic PAP $>60 \mathrm{~mm} \mathrm{Hg}$ ) had relatively poor outcomes. Our results have shown that RMA was able to improve hemodynamics and symptoms in these patients. However, the lack of an untreated control group did not allow us to investigate the survival benefit conferred by RMA for patients with significant MR and severe LV dysfunction. Additional studies of late mortality after RMA in similar patient populations are needed.

\section{Study Limitations}

The main limitations of the present study were its retrospective nature and the small number of subjects. The inclusion of patients with ischemic and nonischemic cardiomyopathy and those who had undergone concomitant coronary artery bypass grafting, tricuspid annuloplasty, and a maze procedure for atrial fibrillation might have influenced the results. However, these concomitant procedures are usually required in a population of very sick patients who present with similar clinical and pathophysiologic status despite the etiology of LV dysfunction. To minimize the potential bias related to patient selection, our study population consisted only of patients with advanced nonischemic or ischemic cardiomyopathy owing to anterior infarction and functional MR. Patients with less LV remodeling and ischemic MR secondary to predominant inferior/posterior infarction, who have often been included in previous studies, ${ }^{6-8,15,16,21,24}$ were excluded from our study. Therefore, our results would not be applicable to patients with previous inferior or lateral infarction.

During the late follow-up examinations, systolic PAP was determined noninvasively using Doppler echocardiography and not measured by catheterization. This noninvasive method has been fully validated and currently represents a standard approach for $\mathrm{PH}$ determination. In the present study, we confirmed that systolic PAP estimated using Doppler echocardiography correlated significantly with the nonsimultaneously catheter-derived systolic PAP $(r=.833, P<.001)$. Moreover, Bland-Altman analysis showed that the 2 modalities had good agreement in the measurements of systolic PAP, although it was slightly overestimated using Doppler echocardiography (mean bias $1.5 \pm 8.4 \mathrm{~mm} \mathrm{Hg}$ ).

The medical treatments administered could have also affected our findings. However, the preoperative medical therapies were continued without significant modifications after surgical intervention. In particular, the use and dosage of angiotensin-converting enzyme inhibitors and angiotensin-II receptor blockers were not changed; thus, their influence on LV remodeling and pulmonary vascular remodeling in our patients was considered to be negligible.

\section{CONCLUSIONS}

Noninvasive assessment of systolic PAP was found to be an excellent prognostic tool for patients who underwent RMA for functional MR secondary to advanced cardiomyopathy. Additional studies are needed to define the mechanism of $\mathrm{PH}$ and its postoperative reversibility in patients with cardiomyopathy to establish new treatment strategies.

The authors thank Kiyoshi Yoshida, CE, and Shin-ichi Fujita for their data collection in regard to surgical intervention and echocardiographic findings. We also thank Hiroyuki Waki for his assistance with the statistical analysis.

\section{References}

1. Abramson SV, Burke JF, Kelly JJ Jr, Kitchen JG III, Dougherty MJ, Yih DF, et al.
Pulmonary hypertension predicts mortality and morbidity in patients with dilated
cardiomyopathy. Ann Intern Med. 1992;116:888-95.
2. Costard-Jäckle A, Fowler MB. Influence of preoperative pulmonary artery pres-
sure on mortality after heart transplantation: testing of potential reversibility of 
pulmonary hypertension with nitroprusside is useful in defining a high risk group. J Am Coll Cardiol. 1992;19:48-54.

3. Bolling SF, Deeb GM, Brunsting LA, Bach DS. Early outcome of mitral valve reconstruction in patients with end-stage cardiomyopathy. J Thorac Cardiovasc Surg. 1995; 109:676-83

4. Crabtree TD, Bailey MS, Moon MR, Munfakh N, Pasque MK, Lawton JS, et al. Recurrent mitral regurgitation and risk factors for early and late mortality after mitral valve repair for functional ischemic mitral regurgitation. Ann Thorac Surg. 2008;85:1537-42.

5. Szalay ZA, Civelek A, Hohe S, Brunner-LaRocca HP, Klövekorn WP, Knez I, et al. Mitral annuloplasty in patients with ischemic versus dilated cardiomyopathy. Eur J Cardiothorac Surg. 2003;23:567-72.

6. Bax J, Braun J, Somer ST, Klautz R, Holman ED, Versteegh MIM, et al. Restrictive annuloplasty and coronary revascularization in ischemic mitral regurgitation results in reverse left ventricular remodeling. Circulation. 2004;110(Suppl II): II-103-8.

7. De Bonis M, Lapenna E, Verzini A, La Canna G, Grimaldi A, Torracca L, et al. Recurrence of mitral regurgitation parallels the absence of left ventricular reverse remodeling after mitral repair in advanced dilated cardiomyopathy. Ann Thorac Surg. 2008;85:932-9.

8. Braun J, van de Veire NR, Klautz RJM, Versteegh MIM, Holman ER, Westenberg JJM, et al. Restrictive mitral annuloplasty cures ischemic mitral regurgitation and heart failure. Ann Thorac Surg. 2008;85:430-7.

9. Nagueh SF, Kopelen HA, Zoghbi WA. Relation of mean right atrial pressure to echocardiographic and Doppler parameters of right atrial and right ventricular function. Circulation. 1996;93:1160-9.

10. Pepi M, Tamborini G, Galli C, Barbier P, Doria E, Berti M, et al. A new formula for echo-Doppler estimation of right ventricular systolic pressure. J Am Soc Echocardiogr. 1994;7:20-6.

11. Kircher BJ, Himelman RB, Schiller NB. Noninvasive estimation of right atrial pressure from the inspiratory collapse of the inferior vena cava. Am J Cardiol. 1990;66:493-6.

12. Taniguchi K, Nakano S, Kawashima Y, Sakai K, Kawamoto T, Sakaki S, et al. Left ventricular ejection performance, wall stress, and contractile state in aortic regurgitation before and after aortic valve replacement. Circulation. 1990;82: 798-807.

13. Bland JM, Altman DG. Statistical methods for assessing agreement between two methods of clinical measurement. Lancet. 1986;1:307-10.

14. Tei C, Ling LH, Hodge DO, Bailey KR, Oh JK, Rodeheffer RJ, et al. New index of combined systolic and diastolic myocardial performance: a simple and repro-

\section{APPENDIX}

The following variables were tested: age, gender, body surface area, NYHA functional class, ischemic etiology, hypertension, diabetes, hyperlipidemia, chronic obstructive pulmonary disease, chronic renal failure, peripheral vascular disease, cerebral vascular disease, atrial fibrillation, history of ventricular arrhythmia, duration of heart failure (in months), multivessel coronary artery disease, previous coronary artery ducible measure of cardiac function—a study in normals and dilated cardiomyopathy. J Cardiol. 1995;26:357-66.

15. Gelsomino S, Lorusso R, Capecchi I, Rostagno C, Romagnoli S, Billè G, et al. Left ventricular reverse remodeling after undersized mitral ring annuloplasty in patients with ischemic regurgitation. Ann Thorac Surg. 2008;85:1319-30.

16. Gelsomino S, Lorusso R, Billè G, Rostagno C, De Cicco G, Romagnoli S, et al. Left ventricular diastolic function after restrictive mitral ring annuloplasty in chronic ischemic mitral regurgitation and its predictive value on outcome and recurrence of regurgitation. Int J Cardiol. 2009;132:419-28.

17. Delgado JF, Conde E, Sánchez V, López-Ríos F, Gómez-Sánchez MA, Escribano P, et al. Pulmonary vascular remodeling in pulmonary hypertension due to chronic heart failure. Eur J Heart Fail. 2005;7:1011-6.

18. Enriquez-Sarano M, Rossi A, Seward JB, Bailey KR, Tajik AJ. Determinants of pulmonary hypertension in left ventricular dysfunction. J Am Coll Cardiol. 1997; 29:153-9.

19. Cody RJ, Haas GJ, Binkley PF, Capers Q, Kelley R. Plasma endothelin correlates with the extent of pulmonary hypertension in patients with chronic congestive heart failure. Circulation. 1992;85:504-9.

20. Moraes DL, Colucci WS, Givertz MM. Secondary pulmonary hypertension in chronic heart failure: the role of the endothelium in pathophysiology and management. Circulation. 2000;102:1718-23.

21. Gelsomino S, Lorusso R, Rostagno C, Caciolli S, Billè G, De Cicco G, et al. Prognostic value of Doppler-derived mitral deceleration time on left ventricular reverse remodelling after undersized mitral annuloplasty. Eur J Echocardiogr. 2008;9:631-40.

22. de Groote P, Millaire A, Foucher-Hossein C, Nugue O, Marchandise X, Ducloux G, et al. Right ventricular ejection fraction is an independent predictor of survival in patients with moderate heart failure. J Am Coll Cardiol. 1998;32: 948-54.

23. Wu AH, Aaronson KD, Bolling SE, Pagani FD, Welch K, Koelling TM. Impact of mitral valve annuloplasty on mortality risk in patients with mitral regurgitation and left ventricular systolic dysfunction. J Am Coll Cardiol. 2005;45:381-7.

24. Fattouch K, Guccione F, Sampognaro R, Panzarella G, Corrado E, Navarra E, et al. POINT: efficacy of adding mitral valve restrictive annuloplasty to coronary artery bypass grafting in patients with moderate ischemic mitral valve regurgitation: a randomized trial. J Thorac Cardiovasc Surg. 2009;138:278-85.

25. Trento A, Goland S, De Robertis MA, Czer LS. COUNTERPOINT: efficacy of adding mitral valve restrictive annuloplasty to coronary artery bypass grafting in patients with moderate ischemic mitral valve regurgitation. J Thorac Cardiovasc Surg. 2009;138:286-8.

bypass grafting, previous percutaneous coronary intervention, $\beta$-blockers, angiotensin-converting enzyme inhibitors, angiotensin-II receptor blocker, diuretics, LVEDD (continuous), LVEDD (>65 mm), left ventricular end-systolic dimension (continuous), left ventricular end-systolic dimension (> $50 \mathrm{~mm}$ ), left atrial dimension, LVEF, tenting height, coaptation length, MR grade, TR grade, systolic PAP (continuous), and severe PH (systolic PAP > $60 \mathrm{~mm} \mathrm{Hg}$ ). 